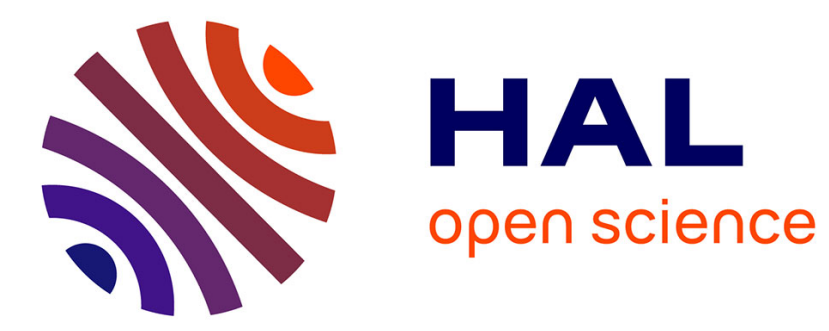

\title{
FES-drop-foot correction: from pre-programmed patterns to online modulation
}

Christine Azevedo Coste, Benoît Sijobert, Jérôme Froger

\section{To cite this version:}

Christine Azevedo Coste, Benoît Sijobert, Jérôme Froger. FES-drop-foot correction: from preprogrammed patterns to online modulation. ICNR: International Conference on NeuroRehabilitation, Oct 2016, Ségovie, Spain. pp.971-974, 10.1007/978-3-319-46669-9_157 . lirmm-01375375

\section{HAL Id: lirmm-01375375 \\ https://hal-lirmm.ccsd.cnrs.fr/lirmm-01375375}

Submitted on 3 Oct 2016

HAL is a multi-disciplinary open access archive for the deposit and dissemination of scientific research documents, whether they are published or not. The documents may come from teaching and research institutions in France or abroad, or from public or private research centers.
L'archive ouverte pluridisciplinaire HAL, est destinée au dépôt et à la diffusion de documents scientifiques de niveau recherche, publiés ou non, émanant des établissements d'enseignement et de recherche français ou étrangers, des laboratoires publics ou privés. 


\title{
FES-drop-foot correction: from pre-programmed patterns to online modulation
}

\author{
Christine Azevedo Coste $*^{1}$, Benoît Sijobert ${ }^{1}$, Jérôme Froger ${ }^{2}$
}

\begin{abstract}
In this communication we will present on going work in our team and recent results towards the improvement of FES-controllers for drop-foot correction in post-stroke survivors. We will insist on challenges to met the way to more adaptive systems.

Most of the results have been already published and we try here to make a synthesis in order to explain our general framework.
\end{abstract}

Walking impairment after stroke can be addressed through the use of drop foot stimulators (DFS). In these systems, electrical stimulation is applied to activate the common peroneal nerve and elicit ankle dorsiflexion during the swing phase of gait. DFS are generally piloted by a heel switch positioned in the shoe of the affected side with stimulation being triggered $\mathrm{ON}$ by heel rise of the affected foot and triggered OFF by heel strike.

Other sensors have been proposed instead of foot-switches such as tilt sensors [1]. Events are the localized on a reference representative pattern and associated to stimulation triggering.

Some closed-loop control approaches have been considered [2] but real-time control of stimulation parameters is still not available in existing devices.

The modulation of FES intensity to provide a more optimized delivery of stimulation and also to regulate dorsiflexion in the presence of disturbances, such as fatigue, may increase the number of potential users of the technology [3]. Modulation of stimulation parameters would enable adaptation to context and environment changes and could match more closely the natural muscle activation patterns. We have proposed a theoretical framework to address dorsiflexion management in post-stroke hemiplegia (figure 1). Our approach consists in considering two levels of observation for the joint control: a local joint observation and a global posture observation. Some of these concepts can be found in [4].

Human gait is a cyclic phenomenon which behavior can be represented by a non-linear oscillator [5]. Based on this, we have proposed a method to monitor the evolution of ongoing gait cycles instead of individual discrete events as in the existing approaches. Our solution relies on a single sensor located on the lower limbs of the walking individual. The parameters of a Van Der Pol oscillator are identified in order to fit with a representative measurement sample of the

\footnotetext{
* contact: christine.azevedo@inria.fr

1 INRIA / LIRMM, Montpellier, France

2 CHU Nîmes/Montpellier - EUROMOV, Montpellier, France
}

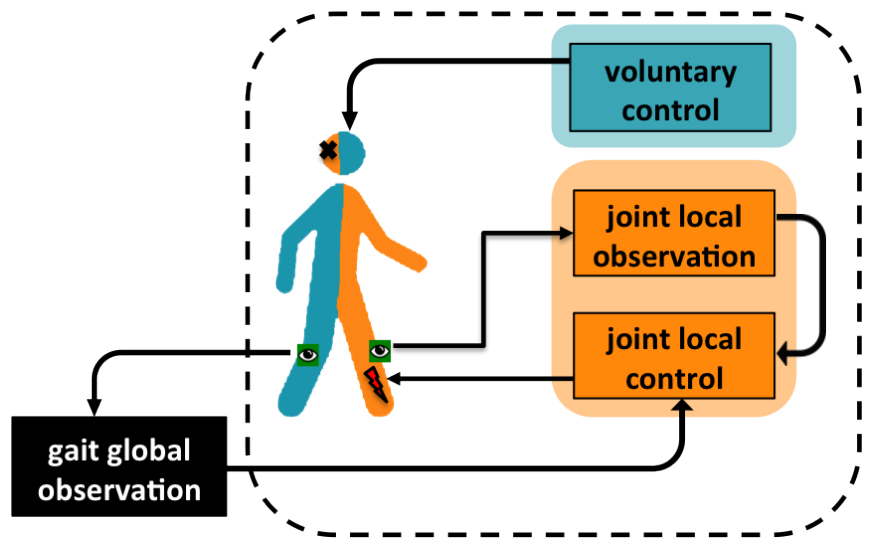

Fig. 1. Observing valid leg movements to control deficient leg muscles in drop foot correction context.

sensor. For instance we can place an inertial sensor on the valid shank and use inclination angle as the reference signal. Based on the oscillator properties, it can be demonstrated that a state observer of the system can be built to estimate the state variables of the oscillator. The phase, which is the coordinate along the limit cycle of the oscillator, can be directly obtained from the estimated system state (fig 2) [6].

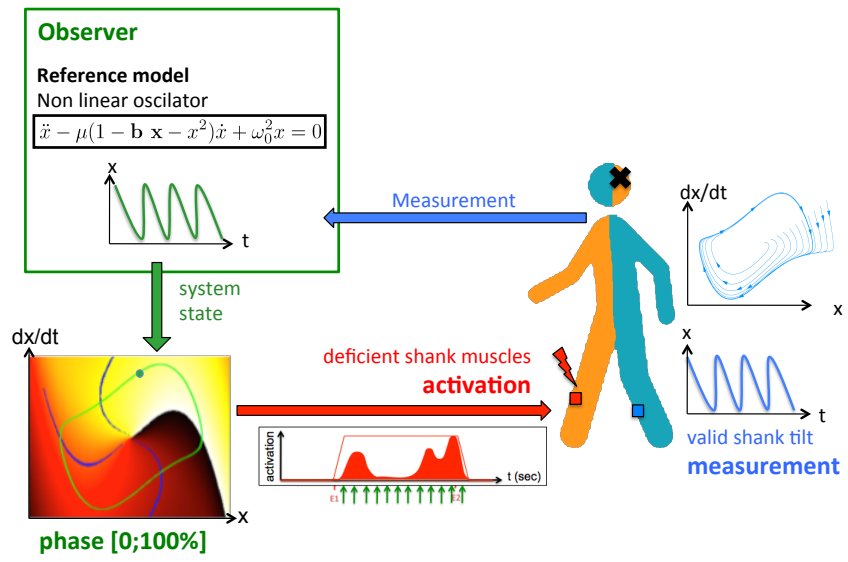

Fig. 2. Observing valid leg movements to control deficient leg muscles in drop foot correction context [4].

We have experimentally validated this approach on 20 post-stroke hemiplegic subjects. We have triggered a drop foot stimulator (Odstock ODFS III) based on the information provided by an inertial sensor located on the valid shank. In other words, we have shown that the observation of shank inclination by means of one inertial sensor allows to get a global information about the gait execution. 
We have also investigated the possibility to associate this approach to optimal control techniques [9], [10]: the swing phase of gait is predicted trough the method described previously (fig 2) and based on the corresponding information, swing phase is predicted. During swing phase, muscle activation is optimized regarding a given set of constraints based on a model of the foot and the tibialis anterior muscle submitted to electrical stimulation. The optimal control problem minimizes the square of muscle excitation which serves the overall goal of reducing energy consumption in the muscle. A Nonlinear Model Predictive Control (NMPC) problem is solved. The optimization problem integrates a set of fixed constraints of foot orientation and an adaptive constraint taking into account the current ankle height. This study was validated in simulation, based on experimental data. This work has now to be extended and validated experimentally in real-time conditions.

In other studies we have also shown that other gait parameters can be obtained from one inertial sensor such a stride length [7], foot clearance [8]. This type of information as well as foot inclination can be integrated in optimal controllers to online compute the FES pattern for the upcoming stride. The big advantage is that instrumentation is minimal and acceptable from a user point of view and satisfies both global and local observation needs (figure 1).

\section{CONCLUSION}

We have described here our general approach of functional assistance using functional electrical stimulation in the context of drop foot correction. Most of the concepts could be adapted to other assistive techniques (orthoses, exoskeletons...). Local stimulation of common peroneal nerve based on local observation of dorsiflexion angle associated to global observation of gait execution may allow to provide adaptive controllers able to adapt electrical stimulation patterns to face muscle fatigue occurrence and context changes.

\section{REFERENCES}

[1] D. Everaert, R. Stein, G. Abrams, A. Dromerick, G. Francisco, B. Hafner, T. Huskey, M. Munin, K. Nolan and C. Kufta, "Effect of a foot-drop stimulator and ankle-foot orthosis on walking performance after stroke: a multicenter randomized controlled trial.", in Neurorehabilitation and Neural Repair, vol.27, no.7, 2013.

[2] P.L. Melo, M.T. Silva, J.M. Martins and D.J. Newman, "Technical developments of functional electrical stimulation to correct drop foot: Sensing, actuation and control strategies.", in Clinical Biomechanics, vol/30, no. $2,2015$.

[3] P.P. Breen, D.T. O'Keeffe,R. Conway and G.M. Lyons, "A system for the delivery of programmable, adaptive stimulation intensity envelopes for drop foot correction applications." in Medical engineering \& physics, vol.28, no.2, 2006.

[4] Ch. Azevedo Coste, B. Sijobert, J. Froger and Ch. Fattal, "Preliminary developments towards closed-loop FES-assistance of posture and gait," in $\{$ IFAC $\}$ Symposium on Biological and Medical Systems $\{B M S\}$, Berlin, Germany, 2015, pp333-337.

[5] R. Héliot and B. Espiau, "Online generation of cyclic leg trajectories synchronized with sensor measurement." in Robotics and Autonomous Systems, vol.56, no.5, 2008.
[6] C. Azevedo Coste, J. Jovic, R. Pissard-Gibollet, J. Froger, "Continuous gait cycle index estimation for electrical stimulation assisted foot drop correction." in Journal of NeuroEngineering and Rehabilitation, vol.11, no.1, 2014.

[7] B. Sijobert, M. Benoussaad, J. Denys, R. Pissard-Gibollet, C. Geny, C. Azevedo Coste, "Implementation and Validation of a Stride Length Estimation Algorithm, Using a Single Basic Inertial Sensor on Healthy Subjects and Patients Suffering from Parkinsons Disease." in Health, Vol.7, no.6, 2015.

[8] M. Benoussaad, B. Sijobert, K. Mombaur and C. Azevedo Coste, "Robust Foot Clearance Estimation Based on the Integration of FootMounted IMU Acceleration Data,' in Sensors, vol.16, no.1 2016.

[9] R. Héliot, K. Mombaur, C. Azevedo Coste, ”Online CPG-Based Gait Monitoring and Optimal Control of the Ankle Joint for Assisted Walking in Hemiplegic Subjects.", in Modeling, Simulation and Optimization of Bipedal Walking - Springer Berlin Heidelberg, vol.18, 2013.

[10] M. Benoussaad, K. Mombaur and C. Azevedo Coste, "Nonlinear Model Predictive Control of Joint Ankle by Electrical Stimulation For Drop Foot Correction.", in IEEE/RSJ International Conference on Intelligent Robots and Systems (IROS'13), 2013. 